\title{
Nano-silicon carbon hybrid particles and composites for batteries: fundamentals, properties and applications
}

\author{
Yohan Oudarta, Rudy Guicheteaua, Jean-Francois Perrin ${ }^{\mathrm{a}}$, Raphaël Janot ${ }^{\mathrm{b}, \mathrm{d}}$, Mathieu \\ Morcrette $^{b, d}$, Mariana Gutierrez ${ }^{a, b}$, Laure Monconduit ${ }^{c, d}$, Nicolas Louvain ${ }^{c, d}$
}

a) Nanomakers, 1 rue de Clairefontaine,78120 Rambouillet, France

b) Laboratoire de Réactivité et Chimie des Solides, UMR CNRS 7314, Université de Picardie Jules Verne, Hub de l'énergie, 15 Rue Baudelocque, 80000 Amiens

c) ICGM, Univ. Montpellier, CNRS, ENSCM, Montpellier, France

d) Réseau sur le Stockage Electrochimique de l'Energie (RS2E), FR CNRS 3459, Hub de l'Energie, Amiens, France

\section{Introduction}

Silicon nanoparticles have interesting properties for Li-ion batteries. Today, batteries use graphite (natural or synthetic) as negative electrode. Graphite is used as anode active material since the very beginning of Li-ion batteries and compared to the positive active materials, its evolution has remained low and is mainly centered on the interface with electrolyte for improved durability at high temperature. Graphite is particularly interesting for its good stability during electrochemical cycling, its low cost, its large availability and its relatively high capacity (350-375 mAh/g based on the $\mathrm{LiC}_{6}$ formation versus $180-250 \mathrm{mAh} / \mathrm{g}$ for cathode active materials). Its main drawback is the quasi-absence of improvement perspectives for capacity. Other materials offer potentially much larger capacities, among them silicon and lithium appear to be the most promising with storage capacities of 3579 $\mathrm{mAh} / \mathrm{g}$ (for $\mathrm{Li}_{15} \mathrm{Si}_{4}$ phase) and $3860 \mathrm{mAh} / \mathrm{g}^{1}$, respectively. They both have very good capacities, large availabilities (contrarily to germanium for instance) and good techno-economical potential. However, lithium faces large technological challenges which have not been solved yet: anode volume expansion with loss of contact with the current collector, with dendrites formation and unreacted lithium are the main challenges. ${ }^{2}$

This chapter will explain why nano-silicon/carbon hybrids particles have strong interest for Li-ion applications, especially to limit SEI (Solid Electrolyte Interface) related irreversible capacities. This is made possible by the association of a rather old chemistry (carbon) with silicon particles nanotechnologies to form an active $\mathrm{Si} / \mathrm{C}$ material. This material meets various well-defined requirements: mainly performances in terms of cycling stability at high capacity values (at least 600 $\mathrm{mAh} / \mathrm{g}$ ) along with cost effectiveness. 


\section{Nano-silicon for batteries}

\section{a. Silicon generalities}

Silicon has a huge interest for energy storage, due to its ability to form alloys with lithium. This property has been largely studied ${ }^{3},{ }^{4}$ and the main alloys at room temperature are $\mathrm{Li}_{13} \mathrm{Si}_{4} ; \mathrm{Li}_{7} \mathrm{Si}_{3} ; \mathrm{Li}_{12} \mathrm{Si}_{7} \mathrm{LiSi}$ and $\mathrm{Li}_{22} \mathrm{Si}_{4}$ as found in the Li-Si binary phase diagram. The $\mathrm{Li}_{22} \mathrm{Si}_{5}$ alloy is the richest in lithium and has a theoretical capacity of $4200 \mathrm{mAh} / \mathrm{g}$ but its formation is not observed under normal electrochemical conditions. Their electrochemical domain is illustrated below along with the corresponding volume changes and particles size increases.

In situ XRD studies indicates that the lithiation of crystalline silicon is made progressively, leading to a succession of amorphous alloys. ${ }^{\text {Erreur ! Signet non défini.,Erreur ! Signet non défini., 5, } 67}$

By in situ NMR spectroscopy, some lithium silicon alloys have been observed along discharge and charge cycling and have been attributed to amorphous $\mathrm{Li}_{2} \mathrm{Si}, \mathrm{Li}_{3.5} \mathrm{Si}$ and crystalline $\mathrm{Li}_{3.75} \mathrm{Si}\left(\mathrm{Li}_{15} \mathrm{Si}_{4}\right)^{8,9,10}$. At the end of discharge below $50 \mathrm{mV}$, the crystallized $\mathrm{Li}_{15} \mathrm{Si}_{4}$ phase is observed. ${ }^{11,12,13}$.For this alloy, the volumic expansion is $270 \%$. Erreur ! Signet non défini., $14,{ }^{15}$ For spherical particles, it means a particle diameter increase of $55 \% .{ }^{16-17}$ The following MET picture indicates that reduction is progressive from the separator side. ${ }^{17}$ After delithiation, silicon is amorphous.

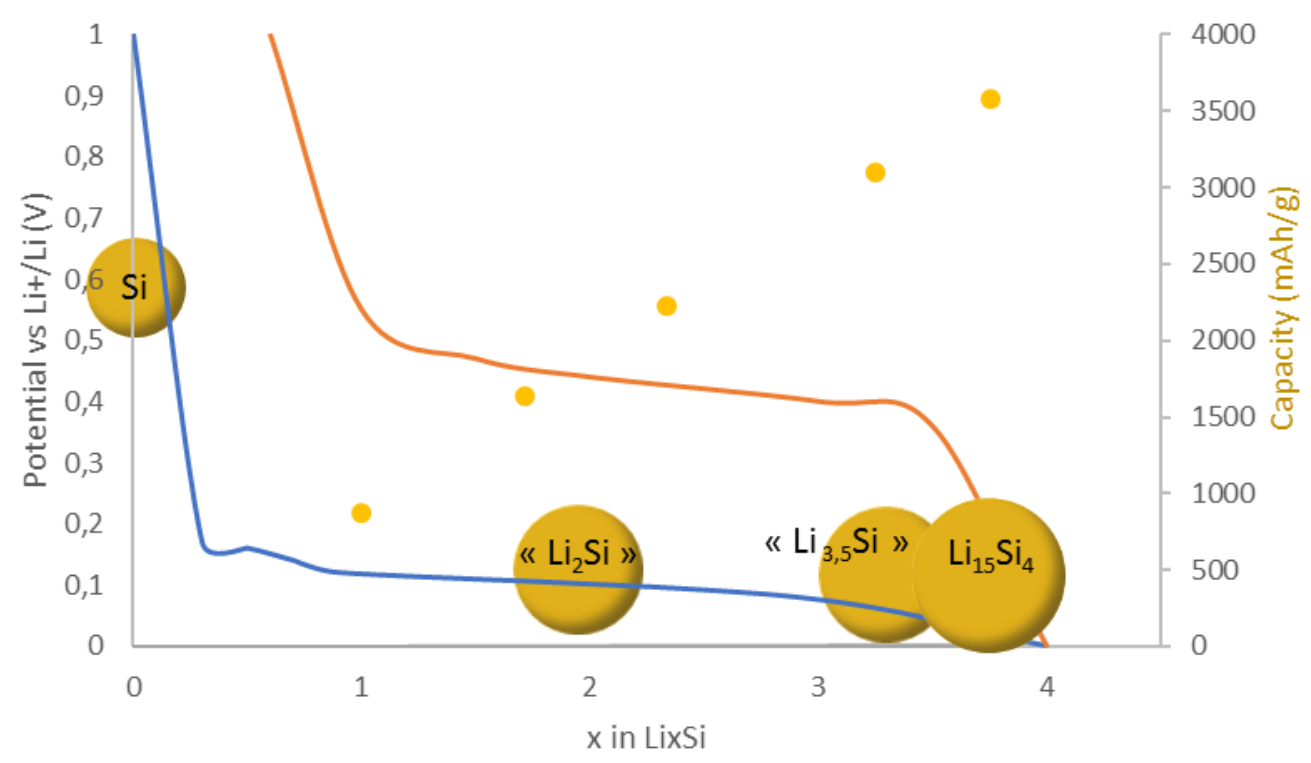

Figure 1: Silicon particle size evolution and LixSi alloy stoichiometry during lithiation (corresponding

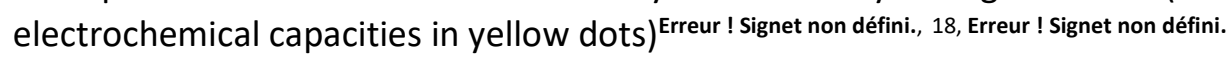




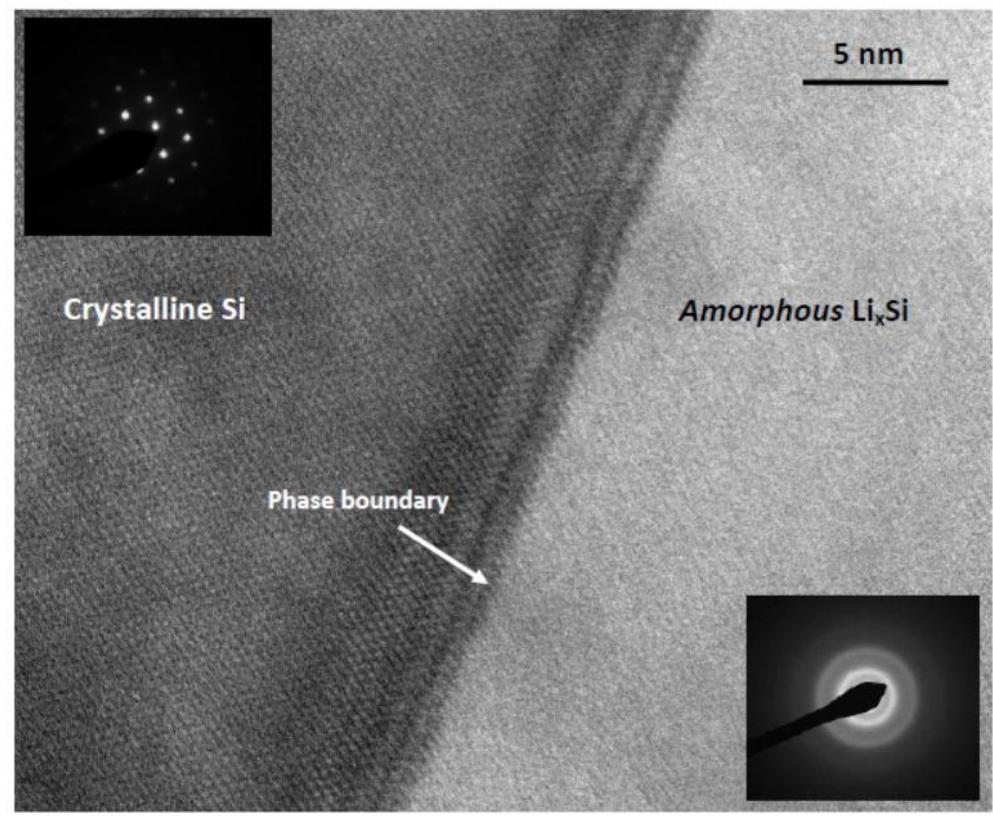

Figure 2: TEM image of silicon electrode after partial lithiation ${ }^{17}$

In the case of particle, lithiation occurs at the surface of the silicon particles. Uncompleted lithiation can leave a crystalline core surrounded by a lithiated surface.

\section{b. Nanosizing}

Due to the high volumetric expansion during cycling (up to $270 \%$ for the $\mathrm{Li}_{15} \mathrm{Si}_{4}$ phase), decrepitation is observed for particles larger than $150 \mathrm{~nm} \cdot{ }^{19,20,21}$ This leads to electrode cracking at large scale as shown below with a silicon wafer. ${ }^{22,17}$

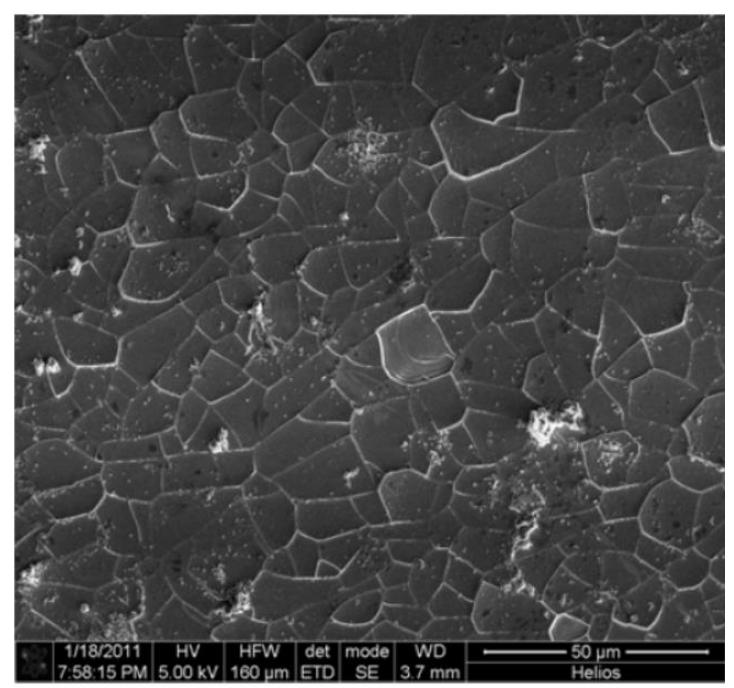

Figure 3: SEM picture of a silicon wafer, showing fractures after delithiation. ${ }^{17}$

During cycling, the particles bigger than $150 \mathrm{~nm}$ fracture progressively and this has two detrimental effects on the electrochemical cycling stability: electrical contact within the electrode materials is partially lost and the particles surface is drastically increased. ${ }^{22,17}$ 
A way to avoid swelling and cracking is the use of only a small fraction of the silicon by reducing the voltage range (especially by increasing the low cut-off voltage) to limit lithiation and swelling. This has been made with micrometric particles. ${ }^{23}$ However, in those types of formulation, the silicon capacity is reduced to $1000 \mathrm{mAh} / \mathrm{g}$, meaning that $72 \%$ of the silicon is unused.

\section{c. Various forms of nano-silicon}

To get particles below $150 \mathrm{~nm}$, the main approach is bottom-up particles preparation. Indeed, the topdown approach is usually based on particles crushing leading to large size distribution, especially with difficulties to avoid some large particles. ${ }^{22}$ Moreover such low particles size requires usually ball-milling in liquid media with solvent under inert atmosphere and high energy.

Bottom-up approach enables a much better control on the particle morphology and size distribution. The different forms are:

- $\quad$ Nanofilms $s^{24}$

Despite good specific capacities, the overall anode surface capacity is limited as the electrode thickness is very low. Thickness increase leads to a sharp decrease of the electrochemical performances..$^{25}$

- $\quad$ Nanowires ${ }^{26}$

Those 1D material includes nanotubes ${ }^{27}$ and nanowires. ${ }^{26}$ Their interest is that they can grow directly on the current collector with a limited use of conductive additives and binders. Energy densities can be high but as the length of the tubes and wires is limited, the anode overall surface capacity is usually low..$^{28,29}$

- Spherical particles and string of spherical particles ${ }^{28}$

Laser pyrolysis is a well know technique for nano-silicon synthesis. It has been reported for the first time in 1980 by Mara. ${ }^{30}$ In a way similar to most bottom-up approaches, the precursor is a gas, usually silane or chlorosilane. The silicon-hydrogen bonds are excited and broken by a $\mathrm{CO}_{2}$ laser leading to the direct formation of silicon and dihydrogen (with silane). The use of a laser enables a very good control of the reaction zone and, therefore, of the particle size distribution. ${ }^{31}$ This method has been scaled up to industrial size. ${ }^{29}$ Powders obtained by this process have spherical primary particles aggregated as strings of few particles. As a negative electrode the powder state enables various formulations and high loadings. ${ }^{85}$ 


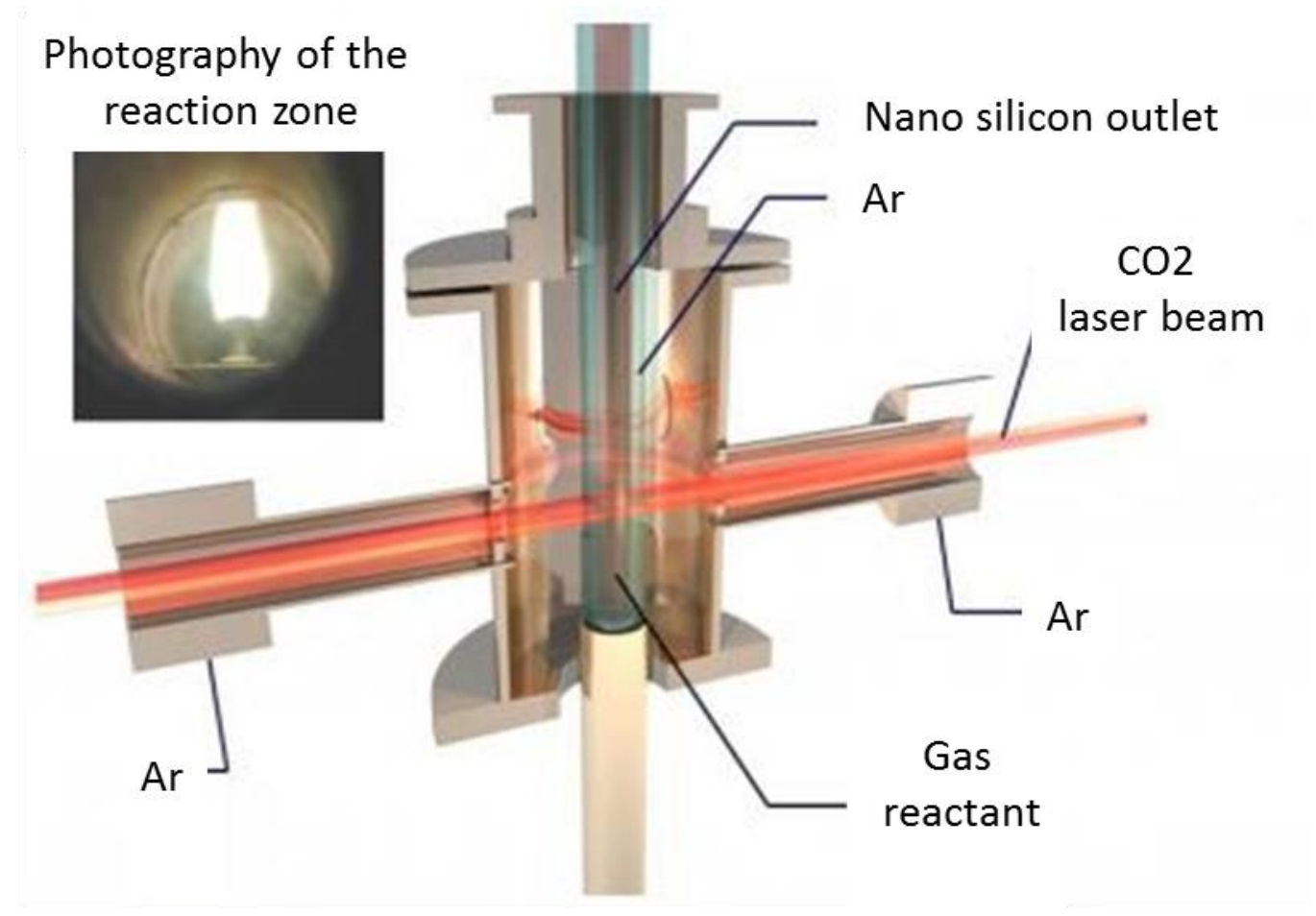

Figure 4: Principle of laser pyrolysis ${ }^{31}$

\section{d. General behavior and SEI}

Silicon nanoparticles solve the cracking problem, but they develop high surface areas: $150 \mathrm{~nm}$ spherical particles have a surface area of $17 \mathrm{~m}^{2} / \mathrm{g}$ for instance and $65 \mathrm{~m}^{2} / \mathrm{g}$ for $40 \mathrm{~nm}$ spherical particles. During complete silicon lithiation, a low potential is reached and the electrolyte salt and solvent reacts with the particles and form the well documented SEI. ${ }^{52}$ This usually occurs at potential below $0,8 \mathrm{~V}$ vs $\mathrm{Li} / \mathrm{Li}^{+}{ }^{32,33}$ An irreversible consumption of lithium and silicon occurs. This layer has a good ionic conductivity but a poor electronic conductivity. ${ }^{33,19,34}$ To form a stable layer, a "formation cycle "is usually run at a slower C-rate than the following cycles or higher temperature. During cycling, the volume expansion can leave new bare silicon surfaces. The SEI is form at the interface and causes an increase irreversible capacity upon subsequent cycling. . Many works are under way to improve the electrolyte in order to form a more stable SEI ${ }^{35,19}, 36,37$ :

$$
\begin{gathered}
\mathrm{LiPF}_{6} \rightarrow \mathrm{LiF}+\mathrm{PF}_{5} \\
\mathrm{PF}_{6}{ }^{-}+2 \mathrm{e}^{-}+3 \mathrm{Li}^{+} \rightarrow 3 \mathrm{LiF}+\mathrm{PF}_{3} \\
\mathrm{PF}_{5}+\mathrm{H}_{2} \mathrm{O} \rightarrow 2 \mathrm{HF}+\mathrm{POF}_{3}
\end{gathered}
$$

Around silicon particles, the usual surface layer is made of silicon oxide (Si-O-Si) and silanol groups (Si$\mathrm{OH})$. This oxide can react with the decomposed $\mathrm{PF}_{6}{ }^{-}$anion to $\mathrm{SiO}_{x} \mathrm{~F}_{\mathrm{y}}$ species and $\mathrm{HF}$ can also form $\mathrm{SiF}_{6}{ }^{2-}$ anions. Those compounds form cracks at the Si particles surface. Interestingly, those cracks are less important for Si particles smaller than $150 \mathrm{~nm} \cdot{ }^{19}$

The classical solvents of the electrolyte are alkyl carbonates that can also react with the silicon and the fluorinated SEI (containing species like LiF, $\mathrm{LiP}_{x} \mathrm{~F}_{\mathrm{y}}$ et $\mathrm{LiPO}_{y} \mathrm{~F}_{z}$ ) thus increasing irreversible capacities. This phenomenon is more important with small particles and larger specific surface areas. ${ }^{19}$ 
The SEl containing organic and inorganic species is formed upon the first lithiation but also evolves upon subsequent cycling in the case of $\mathrm{Si}$ due to volumetric expansion, crackings, and exposure of fresh surfaces. This is the main drawback of silicon as negative electrode for Li-ion batteries. Two main complementary ways are investigated as workarounds:

- modifying the electrolyte formulation to make it more stable upon cycling by the use of additives such as FEC and VC. ${ }^{38}$ This is not the topic of this chapter.

- protecting the silicon to reduce and stabilize the SEI formation. This chapter describes the most documented approaches which is the use of carbon.

\section{Carbon}

Carbons are the most used materials for Li-ion batteries. The chemical stability and specific capacity of graphite made it the most efficient material in batteries. This paved the way for the first Li-ion batteries commercialization by Sony in 1991 based on Yoshino et al. patent. ${ }^{39}$

Table 1: Comparison of the performances of graphites and silicon ${ }^{40}$

\begin{tabular}{|c|c|c|c|}
\hline & Artificial graphite & Natural graphite & Si \\
\hline $\begin{array}{c}\text { Capacity } \\
\text { (mAh/g) }\end{array}$ & 365 & 350 & Up to 3576 \\
\hline $\begin{array}{c}\text { First irreversible } \\
\text { capacity }\end{array}$ & $90-94 \%$ & $90 \%$ & $\begin{array}{c}75-80 \% \text { without C } \\
\text { protection and usual } \\
\text { formulation, up to } 90 \% \\
\text { with coating }\end{array}$ \\
\hline $\begin{array}{c}\text { Metric Tonnage } \\
2017\end{array}$ & 70000 & 50000 & $<10 \mathrm{t}$ \\
\hline
\end{tabular}

To combine the stability of carbon with the capacity of silicon, the mix of silicon and carbon (mainly graphite) has been tested. This way is simple but requires the development and use of specific binders which are not always easily and economically available. This is why nanoparticles of silicon hybridized with carbon have been developed.

One important feature is the thermodynamically favorable reaction of silicon with carbon to form silicon carbide which is not active for lithium storage ${ }^{41}$ and thus its formation should be avoided.:

$$
\mathrm{Si}+\mathrm{C} \rightarrow \beta-\mathrm{SiC} \Delta \mathrm{H}_{\mathrm{f}}=-73.2 \mathrm{~kJ} / \mathrm{mol} \text { for } \beta-\mathrm{SiC} \text { at } 298 \mathrm{~K}^{42}
$$

However, the activation energy for this reaction is high and it does not occur below $900-1000^{\circ} \mathrm{C}$. On the other hand, graphite is the best carbon phase for lithium storage but its formation requires hours of crystallization at temperatures above $2400^{\circ} \mathrm{C} .{ }^{43}$ Therefore, graphite/silicon composites can only be made by mixing and not by synthesis, without direct bonds between them. Some teams succeeded in forming graphene coating ${ }^{44}$ on silicon thanks to a very special CVD parameters set: $\mathrm{CH}_{4}$ and $\mathrm{CO}_{2}$ at $1000^{\circ} \mathrm{C}$ leads to graphene growth on silicon whereas at $900^{\circ} \mathrm{C}$ graphene is not well formed and at $1100^{\circ} \mathrm{C}$ silicon oxide layer was too thick. Without $\mathrm{CO}_{2}$, $\mathrm{SiC}$ is readily formed. In full cells configuration, 
capacity drops by $28 \%$ after 200 cycles, with an initial capacity of $970 \mathrm{mAh} / \mathrm{g}$. These results were achieved with $100 \mathrm{~nm}$ silicon powder.

However, other forms of carbon can store lithium and can be useful for silicon hybridization.

\section{a. Carbon forms}

Two properties are important for carbon as anodes materials: electrical conductivity and lithium insertion/intercalation. Both of those properties are favored with the presence of conjugated aromatic cycles. ${ }^{45}$ In the specific case of graphite, plans of graphene are perfectly aligned and this favors electric transfer. Aromatic content and graphitization are favored by temperature, graphite being formed above $2400^{\circ} \mathrm{C}$ (see Figure 5). Lithium intercalation is made between the graphene sheets yielding to its good storage capacity ( $372 \mathrm{mAh} / \mathrm{g}$ ). This reversible intercalation is usually summarized as:

$$
\mathrm{Li}+6 \mathrm{C} \rightarrow \mathrm{LiC}_{6} .
$$

Lithium diffusion is important for lithiation and delithiation processes. A well-structured phase will enable a good permeability and a good intercalation of lithium. As a general principle, the more structured carbon, the better stable lithiation capacity: up to $372 \mathrm{mAh} / \mathrm{g}$ for graphite, $220 \mathrm{mAh} / \mathrm{g}$ for carbon black (Super P) ${ }^{46}, 290 \mathrm{mAh} / \mathrm{g}$ for petroleum pitch (Rutgers $\left.250 \mathrm{M}\right)^{47}$ with very disordered species but high aromatic contents. For cokes, compositions are various, initial capacities range from 500 to $800 \mathrm{mAh} / \mathrm{g}$ after treatment at $800^{\circ} \mathrm{C}$ but decrease below $200 \mathrm{mAh} / \mathrm{g}$ after few tens of cycles. Oxidation can improve stability around $400 \mathrm{mAh} / \mathrm{g}$ but with $200 \mathrm{mAh} / \mathrm{g}$ capacity loss during the first 20 cycles. ${ }^{48}$ Moreover, the higher thermal treatment temperature is performed, the better is the graphitization.

\section{Development of Crystallite Alignment}

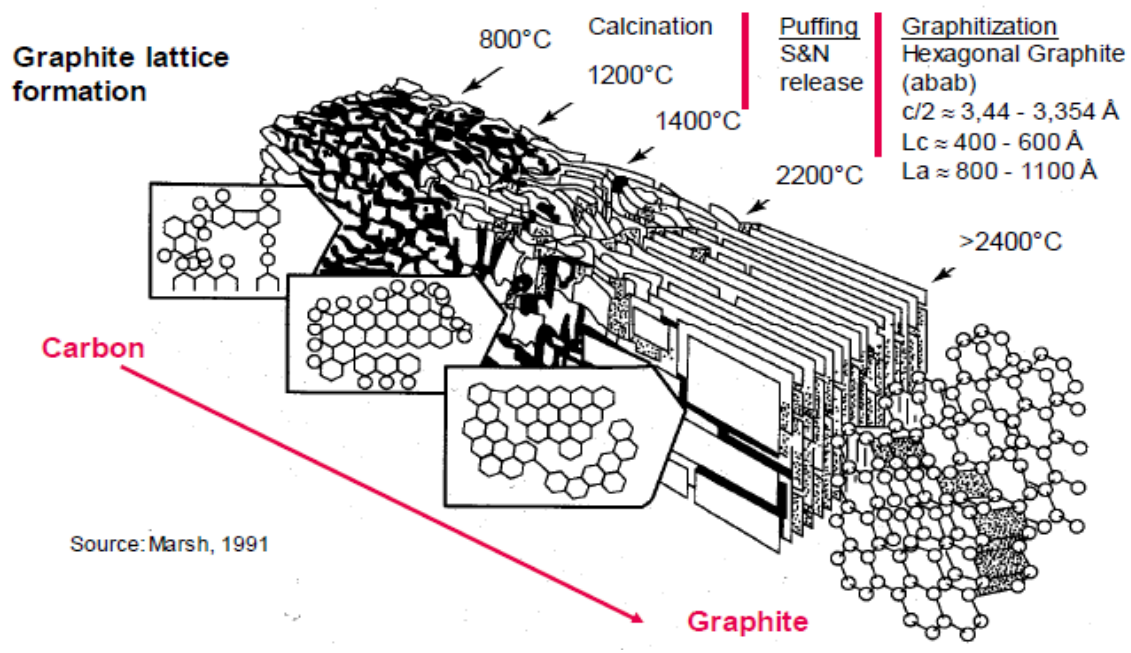

Figure 5: Carbon structure evolution from mesophase depending on temperature. ${ }^{49}$

For carbon treated at temperature up to $1000^{\circ} \mathrm{C}$, the structure and the lithiation property will also depend on the precursor type, mainly soft and hard carbon with the main different is that soft carbon can be transformed into graphite at high temperature and this is not the case of hard carbons due to a high content of structural defects. For example, soft carbons can be made from pitch at $900-1000^{\circ} \mathrm{C}$. Those structures can have capacities higher than graphite as they have many structural defaults and microporosity along with small graphitic domains..$^{50,51}$ They however have large irreversible capacity at first cycle and high polarization between charge and discharge..$^{51}$ 


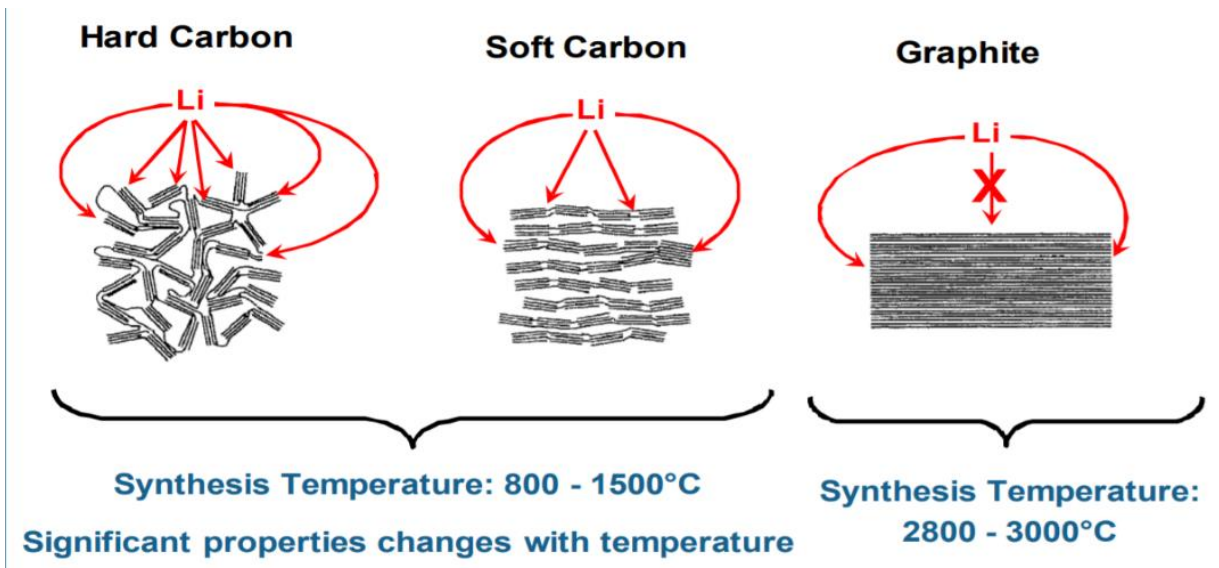

Figure 6: Comparaison entre les différents carbones ${ }^{52}$

Hard carbons are obtained from oxygen or sulfur rich precursors at temperature superior to $1000^{\circ} \mathrm{C}$. Oxygen and sulfur enable partial graphitization but along with reticulation, disabling full graphitization. Typical precursors are cellulose, sucrose... Oxygen control and precursor oxygen content is rather important.

Nanosilicon $\left(<80 \mathrm{~nm}\right.$ ) is oxidized slowly from $500{ }^{\circ} \mathrm{C}$ and rapidly from $800^{\circ} \mathrm{C} .{ }^{29}$ Silicon oxidation into silicon dioxide is thermodynamically favored and exothermic $\left(\Delta \mathrm{H}_{\mathrm{fliq}}=-902.7 \mathrm{~kJ} / \mathrm{mol}\right)$ and is one of the most stable form of silicon. ${ }^{69}$

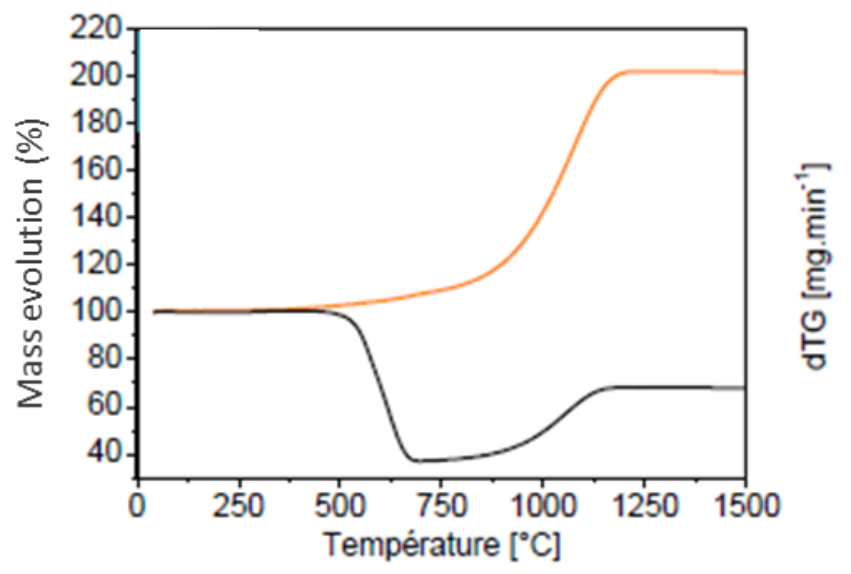

Figure 7: Thermogravimetric analysis of pure nanosilicon particles (red) and carbon coated silicon nano particles containing $60 \%$ carbon (black) ${ }^{53}$

As silicon oxide capacity and also initial irreversible loss are less good than pure silicon, its oxidation should be avoided by the absence of oxygen or oxygen precursors (oxygen rich carbons) during thermal treatments. Carbon oxidation can occur earlier and independently from silicon oxidation (see thermogravimetric analysis for carbon coated Si particles in Figure 7).

To avoid oxygen, nitrogen can be used; however, nitridation of silicon from $\mathrm{N}_{2}$ gas is also thermodynamically very favorable $\left(\Delta \mathrm{H}_{\mathrm{f}}=-733 \mathrm{~kJ} / \mathrm{mol}\right.$ for the reaction $\left.3 \mathrm{Si}+2 \mathrm{~N}_{2}=\mathrm{Si}_{3} \mathrm{~N}_{4}\right)$ but occurs only at high temperature above $1350^{\circ} \mathrm{C}$, close to silicon melting point $\left(1410^{\circ} \mathrm{C}\right) .^{54}$ 
The temperature value has to be a compromise as higher temperature increases graphitization and improve carbon properties but, inactive $\mathrm{SiC}$ can be formed ${ }^{28,55,56}$ For instance, SiC formation has been observed at temperature as low as $800^{\circ} \mathrm{C}$ for petroleum pitch and polysilane. ${ }^{110}$ However, this low temperature is probably due to the silicon precursor reactivity. With nano silicon and pitch blends, SiC formation with $12 \% \mathrm{Si}$ (atomic) has been observed at $1000^{\circ} \mathrm{C}{ }^{83}$

Along with pyrolysis temperature, physical properties change; Young modulus increases up to $1000^{\circ} \mathrm{C}$ and then decreases: elasticity of the carbon host matrix is the worst at about $1000^{\circ} \mathrm{C}$. From $1500^{\circ} \mathrm{C}$, thermal and electrical conductivities both increase due to the middle and long distances graphitization process (also illustrated in Figure 8 )..$^{43}$

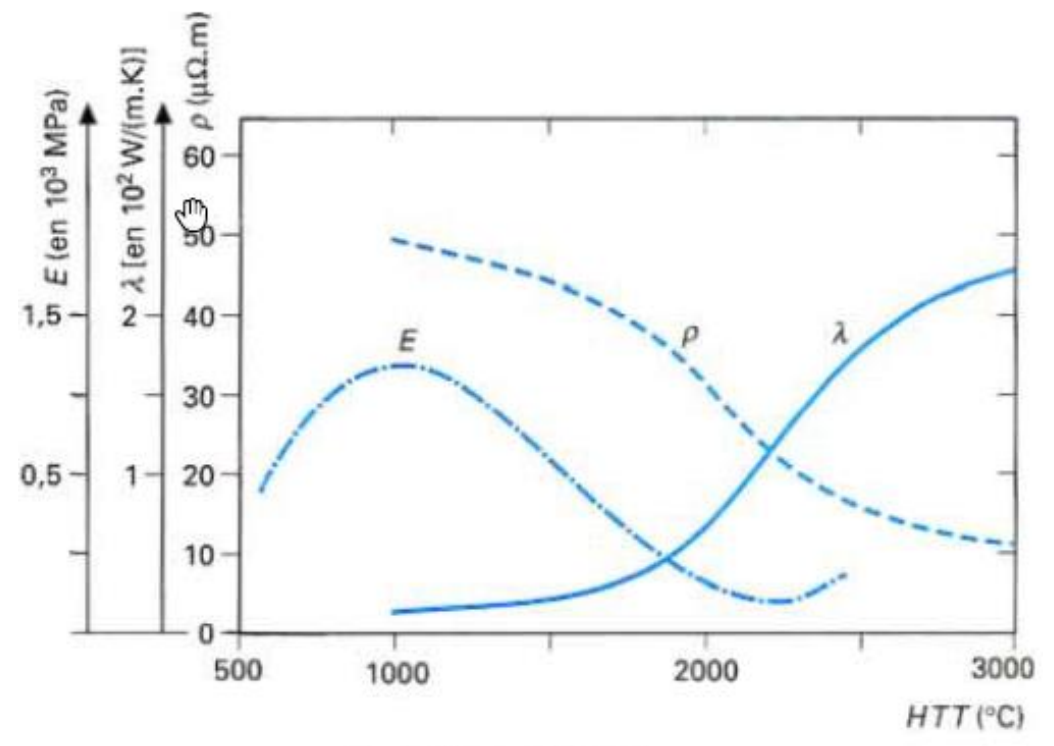

Figure 8: Influence of pyrolysis temperature on physical properties ( $E=$ Young modulus, $\lambda=$ thermal conductivity; $\rho=$ resistivity ${ }^{43}$

\section{b. Pitch as precursor}

Different carbon precursors have been tested ${ }^{57}$ : graphite, PVC, pitches (coal or petroleum), PVA, PAN, PVP, phenolic resins, saccharides, and lignin ${ }^{58}$. The most often used in academic literature are pitches and PVC. At larger scale, PVC is not used as its mass loss during pyrolysis is very high (83\%) and chloride emission are generated and have to be treated. ${ }^{83}$ Erreur! signet non défini.,59 The interest of PVC is the good elasticity of the resulting carbons and the final $\mathrm{Si} / \mathrm{C}$ composites have low specific surface areas.

Pitch is a carbonaceous mixture of organic byproducts resulting from distillation of coal or petroleum, not readily useful for energy production (combustion). Its main characteristics are its high boiling points $\left(>200^{\circ} \mathrm{C}\right.$ ) and its high content in aromatic molecules. Its main application is road covering, and some special grades are used as amorphous carbon coating for graphite electrodes of Li-ion devices.

During pyrolysis of pitch, hydrogen is produced due to aromatization of the molecules. It only explains a minor part of the weight loss which is due to the gasification of carbon material. ${ }^{60}$ This usually ends between 500 and $600^{\circ} \mathrm{C}$ depending on the precursor. Between 350 and $450^{\circ} \mathrm{C}$, polycyclic hydrocarbons of about 10 cycles face condensation reaction and their size increase ${ }^{61,62}$. At temperature of $420-500^{\circ} \mathrm{C}$, a liquid crystal phase called mesophase appears (cf. Figure 9). ${ }^{60}$ 


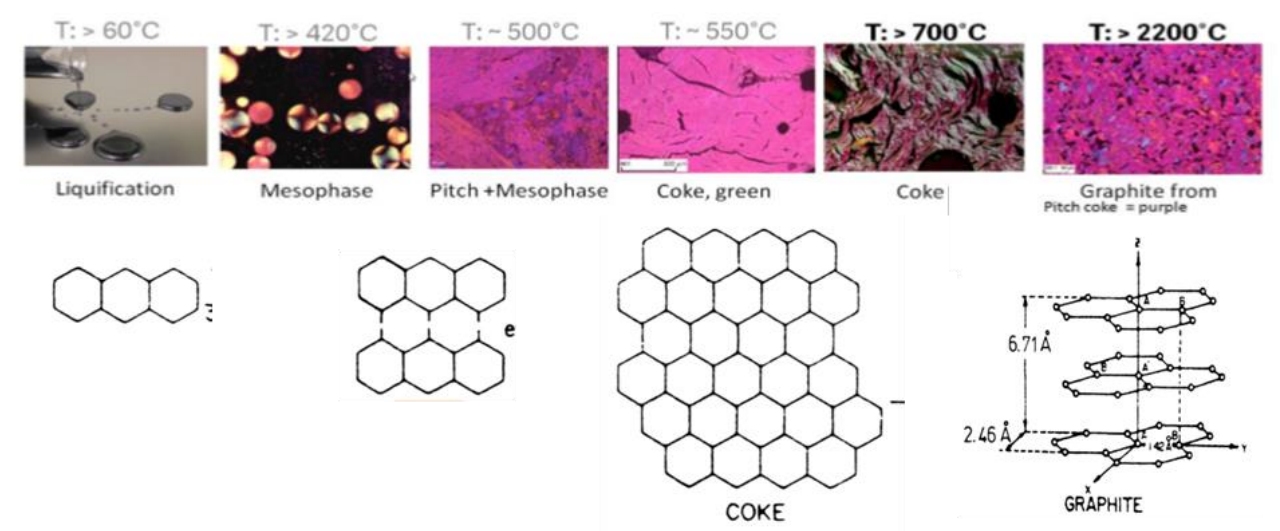

Figure 9: Phase formed during thermal treatment of pitch ${ }^{63,62}$

From temperature over $700{ }^{\circ} \mathrm{C}$ and in all cases at $900{ }^{\circ} \mathrm{C}$, aromatics are the mains molecules. Further temperature increase will mainly improve crystallinity, instead of aromaticity. ${ }^{60}$ The pitch structure contains aliphatic and aromatic compounds in various concentration. The $\mathrm{C}-\mathrm{C}$ and $\mathrm{C}-\mathrm{H}$ bond breaking during aromatization requires energy $(420 \mathrm{~kJ} / \mathrm{mol}$ to break an aromatic $\mathrm{C}-\mathrm{H}$ bond and $325 \mathrm{~kJ} / \mathrm{mol}$ for a $\mathrm{C}-\mathrm{H}$ bond in methyl group). Thus, aliphatic groups will require more energy than aromatic groups to fully decompose in aromatic cycles ${ }^{60}$. On the other hand, the more aromatic compound, the higher activation energy to initiate $\mathrm{C}-\mathrm{H}$ bonds breaking (which is normal as those products are thermodynamically more stable). ${ }^{63}$

Therefore, carbon chemistry is rather complex and difficult to characterize. In most cases, silicon will be associated with non-crystalline carbons even though some graphitic contribution can be observed. For instance, Raman spectroscopy analysis has be done on $30 \mathrm{~nm}$ silicon coated with carbon $(19 \% \mathrm{C}$ in weight) : the spectra show two bands, the one at $1600 \mathrm{~cm}^{-1}$ called $\mathrm{G}$ being attributed to organized graphitic carbon. ${ }^{84}$ whereas the " $\mathrm{D}$ " band corresponds to disorganized carbon. This carbon is made from ethylene decomposed by a $\mathrm{CO}_{2}$ laser.

So apparently, it is not possible to combine all the positive properties of carbon and silicon due to temperature limitation. However various approaches have been developed to combine the most interesting properties of each that is to say silicon capacity and carbon stability.

\section{Carbon coating of silicon}

Many protocols have been used to make a carbon coating on silicon, from solid precursor (mechanosynthesis), carbon dissolved in solution (sucralose, PVC...) or from gas, mainly acetylene.

\section{a. Mechanical milling}

Powders are crushed together in high energy system with hard milling tools (usually hardened steel or tungsten carbide). ${ }^{64, E r r e u r ! ~ s i g n e t ~ n o n ~ d e ́ f i n i ., 65 . ~ D e p e n d i n g ~ o n ~ t h e ~ a p p a r a t u s ~ a n d ~ t h e ~ t a r g e t e d ~ p a r t i c l e ~ s i z e, ~}$ operating milling times range from 1 to $100 \mathrm{~h}$. A temperature increase is usually observed but it remains below $200^{\circ} \mathrm{C} .{ }^{66}$ During crushing, two main mechanisms are encountered: pulverization which tends to form small particles, ${ }^{66}$ and aggregation which has the opposite effect of pulverization in term of mean particle size. ${ }^{64}$ 
This method has been successfully used with various carbon precursors including graphite to obtain $\mathrm{Si} / \mathrm{C}$ composites. It could be followed by thermal treatments. Coating is usually observed and irreversible capacity is decreased even though it is difficult to identify the effect of silicon particle size decrease and coating only itself ${ }^{66,67}$. Despite low temperature, $\mathrm{SiC}$ formation has been reported for highly energetic milling process. ${ }^{19}$ Silicon particle size distribution is usually large and possible contamination by the reactor materials such as iron or tungsten, and their related carbides, can be found (up to few wt. \%) ${ }^{64,68}$.

\section{b. Gas-phase synthesis}

The gaseous way is advantageously a single step process as carbon is directly decomposed onto silicon particles. Acetylene is the main raw material as it is cheap, easily available, and highly exothermic $\left(-243 \mathrm{~kJ} \mathrm{~mol}^{-1}\right.$ at $900 \mathrm{~K}$ for the reaction $\left.\mathrm{C}_{2} \mathrm{H}_{2}=2 \mathrm{C}+\mathrm{H}_{2}\right) .{ }^{69} \mathrm{CVD}$ has been used, ${ }^{75}$ as well as PECVD (plasma enhanced chemical vapor deposition. ${ }^{70}$

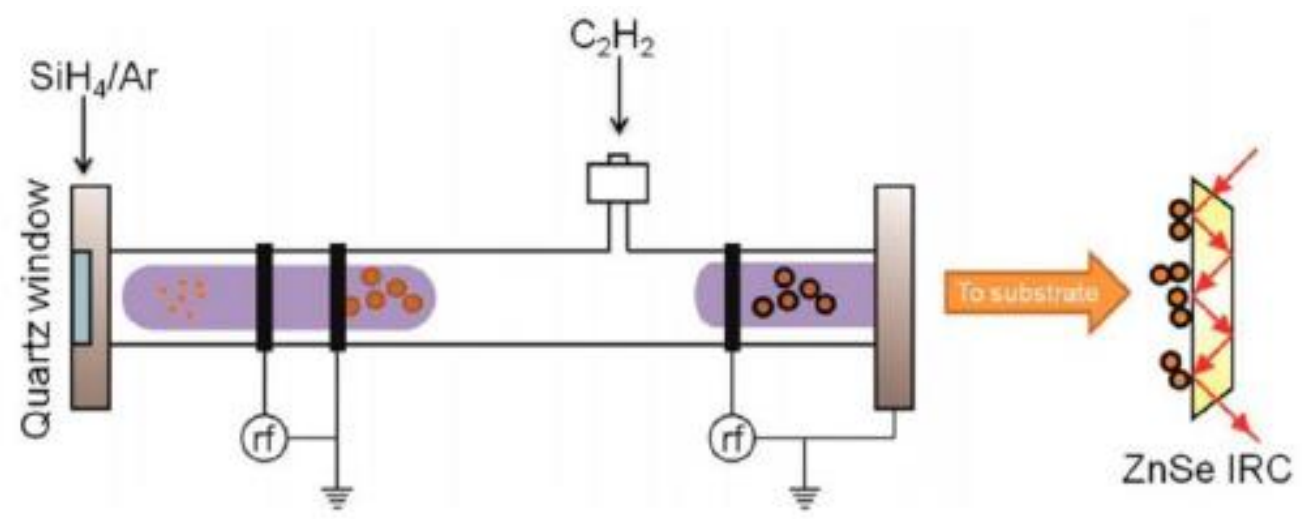

Figure 10: Scheme of plasma reactor for carbon coated silicon particles ${ }^{71}$

Acetylene decomposition starts at the temperature of $700{ }^{\circ} \mathrm{C} .^{72}$ Some silicon surfaces can also catalyze this reaction and lower this temperature down to $600{ }^{\circ} \mathrm{C} .{ }^{73}$ For homogeneity reason, it is preferable that the hot silicon particles meet the colder acetylene gas in order not to decompose acetylene alone and form carbon nanoparticles. ${ }^{29,84}$

To avoid particle handling and a step of aerosol formation, coating in line with silicon nanoparticle production is of strong interest. This has been exemplified by laser pyrolysis with two different systems: acetylene gas injection just after the silicon formation zone. ${ }^{74}$ This method has been demonstrated at several $\mathrm{kg} /$ hours and electrochemical performances are shown below.

Another embodiment is the use of a second reaction zone where the flame is formed via interaction of ethylene and $\mathrm{CO}_{2}$ laser. A radiation flame is observed..$^{29}$ Those approaches validate the interest of carbon coating for silicon surface protection. 

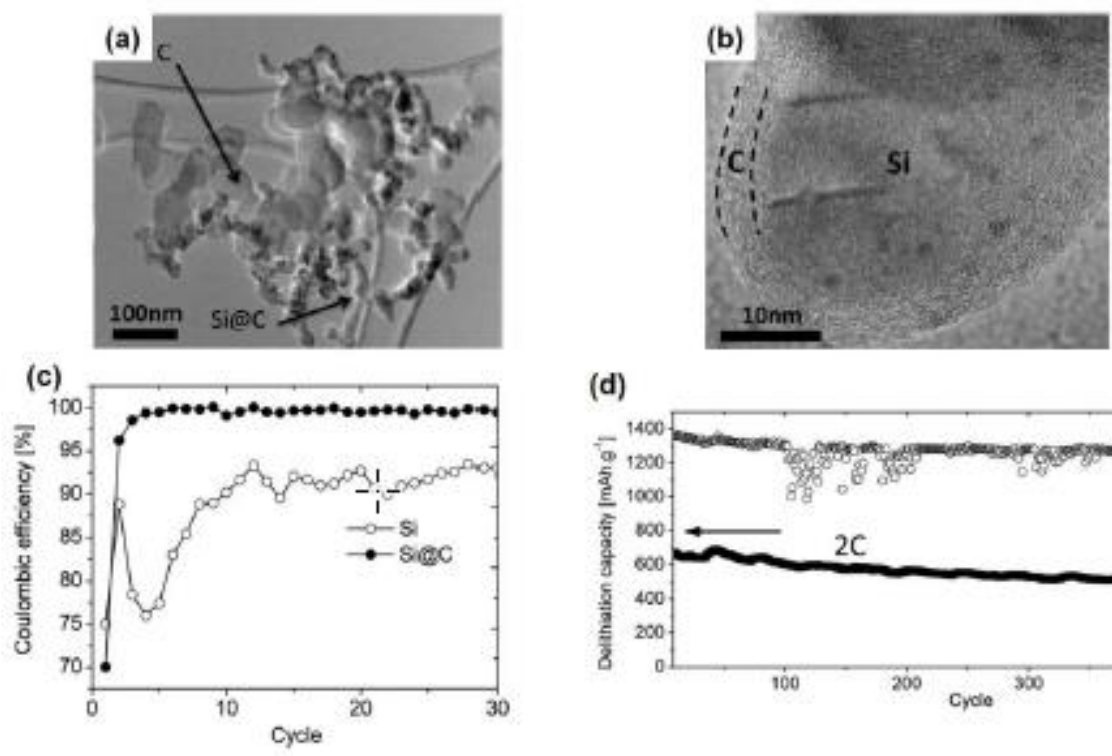

(d)

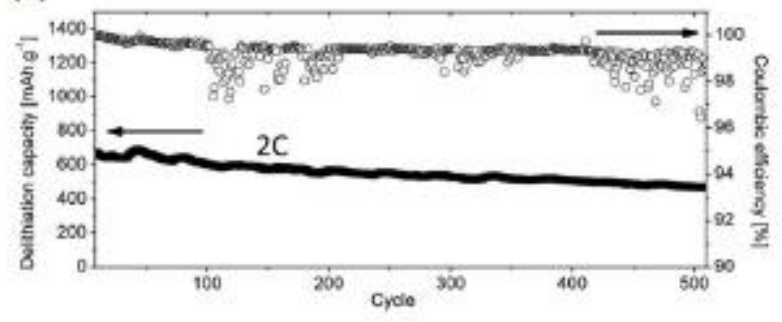

Figure 11: Si@C particles obtained directly from laser pyrolysis and cycling performances obtained ${ }^{53}$

\section{c. Liquid process}

This method is made in four steps:

- Carbon precursor dissolution in a solvent,

- Silicon nanoparticles dispersion in the slurry,

- Solvent removal (usually evaporation),

- Thermal treatment.

A key step is the homogeneity of dispersion of nanosilicon as agglomerates can be formed. Erreur ! signet non défini. High shear system (Dispermat, Ultra-Turrax) can be used and, for small samples preparation, ultrasonication is the most used technique even though it should not be used with flammable solvent (cavitation can cause local temperature increase and ignite inflammation). After the solvent removal, the carbon precursor should be thermally treated to have a good protection of silicon. The effect of thermal treatment is described in the composite section.

Sucrose can be used to obtain a coating on the particles with limited success in term of stability. ${ }^{75}$ The most complex carbon structures have been obtained through the liquid phase route using templates to creates voids between silicon and carbon for instance. The idea is to have enough void to accommodate silicon particles swelling during cycling without breaking the carbon shell. This has improved significantly the silicon stability at rather high capacity values $(1000 \mathrm{mAh} / \mathrm{g})$. The preparation includes several steps, the key one being the covering of particles with a surfactant which is then covered by a silica crust. After surfactant removal, the hollow silica crust is used as a template for carbon deposition. After thermal treatment, this silica layer is removed by HF leaching. ${ }^{76}$ 

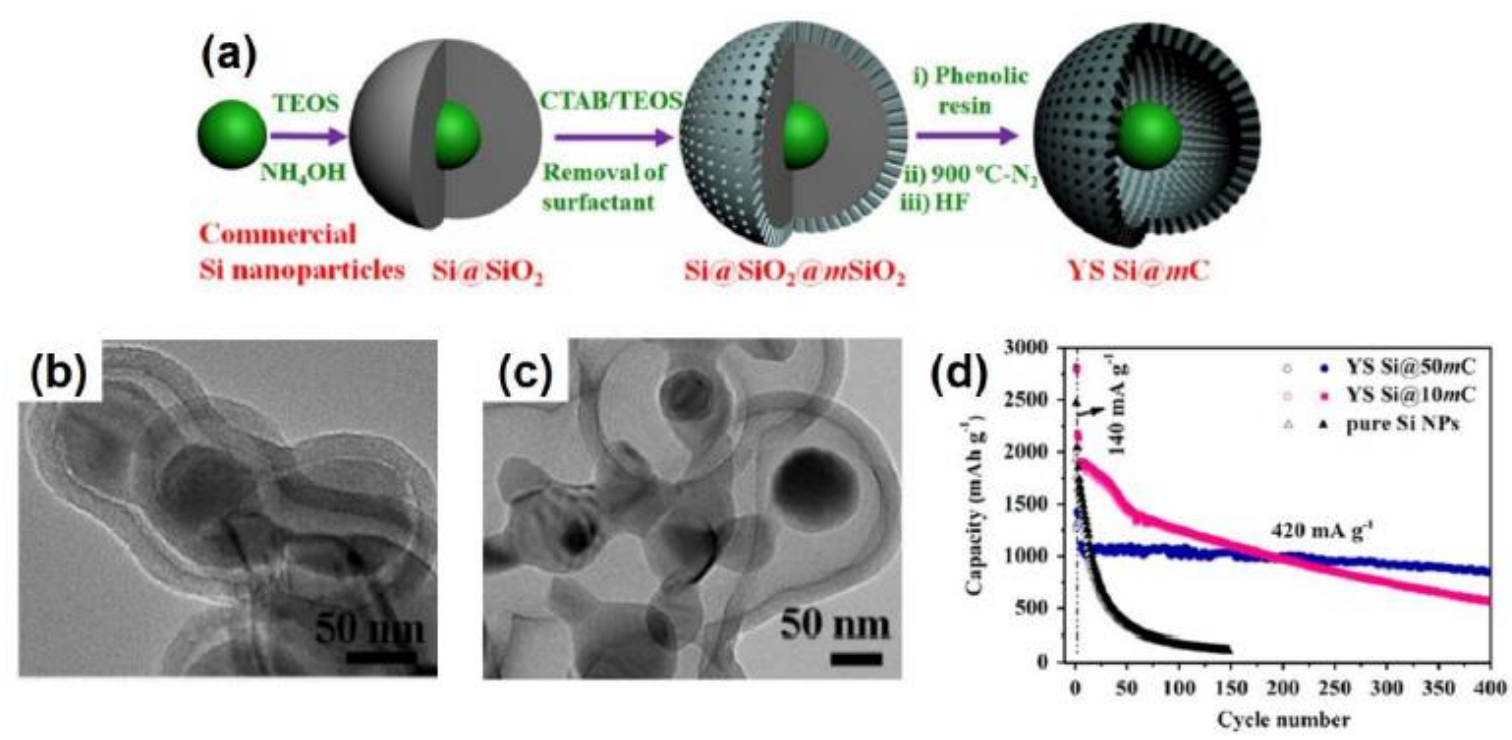

Figure 12: Hollow yolk-shell structure (Si@void@C) and corresponding electrochemical performance ${ }^{76}$

A pomegranate structure has then been obtained with "grains" of silicon inside a hollow carbon shell. Performances are also very stable with high capacities (around $700 \mathrm{mAh} / \mathrm{g}$ ) for thousands of cycles, despite high irreversible losses during the very first cycle (50\%). ${ }^{77}$

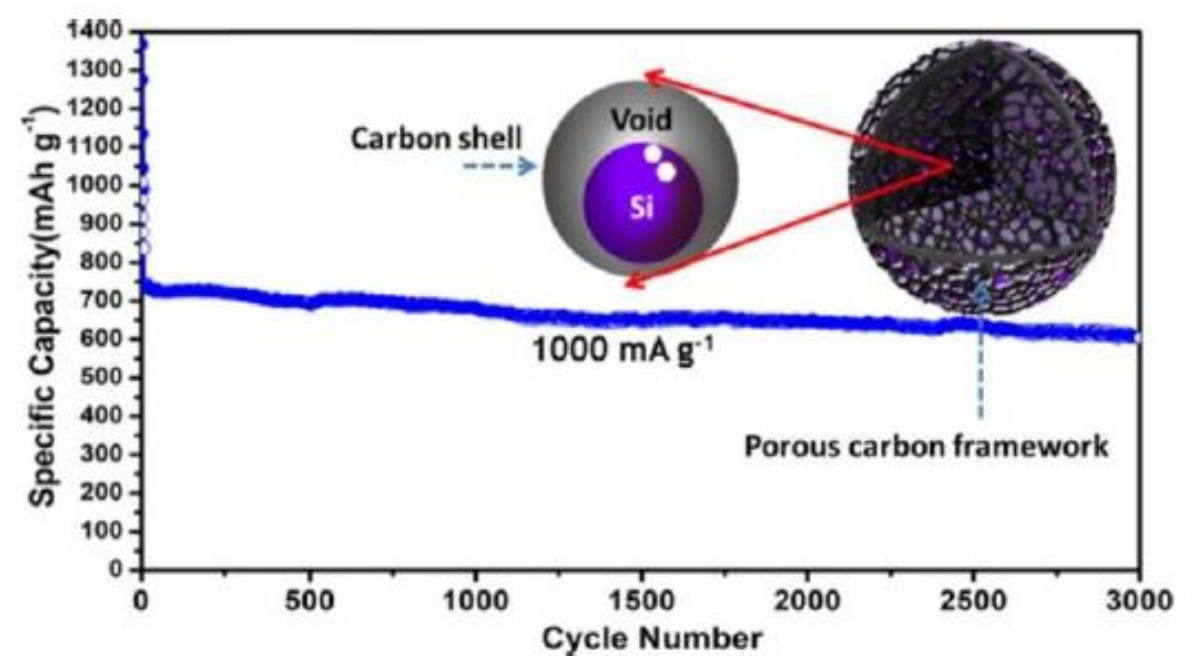

Figure 13: Pomegranate assembly of Si@void@C particles and corresponding chemical performances ${ }^{77}$

This validates the general assumption that swelling side-effects could be limited by having enough space for it. Those preparations would be difficult to scale up economically but validate that silicon can be cycled under stable conditions if the system can accommodate volume expansion. This can be done also using elastic binders in the electrode formulation. 


\section{d. Si/C composites}

The previous section mainly detailed the preparation of thin carbon coating around silicon particles. Another approach is to embed silicon into a carbon matrix to form a $\mathrm{Si} / \mathrm{C}$ composite. The main advantage of this approach is to obtain micrometric particles similar in size to graphite $(10-40 \mu \mathrm{m})$ ready and easy to use. Moreover, carbon protection around silicon is much thicker and tunable ${ }^{57,78,79}$. The main routes are the liquid process (see thin coating part) with the same steps, the main difference being the higher carbon content. For some precursor, especially pitches, it is possible to take advantage of the low temperature melting point to disperse silicon into hot fused carbon, before a thermal step. During solvent evaporation and thermal treatment, some micropores can be created, thus increasing specific surface area and, therefore, irreversible capacity. ${ }^{78}$ Moreover graphite and some other additives can be added in the composite to enhance properties (electronic conductivity, stability,...) This method can for instance yield Si/C/Graphite composite with specific capacity of $80 \%$ after 100 cycles with 17 wt.\% Si and a current density of $130 \mathrm{~mA} / \mathrm{g} \cdot{ }^{57,60,85}$ The carbon matrix act as an intermediate between electrolyte and Si nanoparticles. It avoids direct contact between them and creates a chemically and mechanically stable SEI. ${ }^{80,81} 82,19$

A key step for hybridization is the thermal treatment and it is developed here using pitches as carbon precursors.

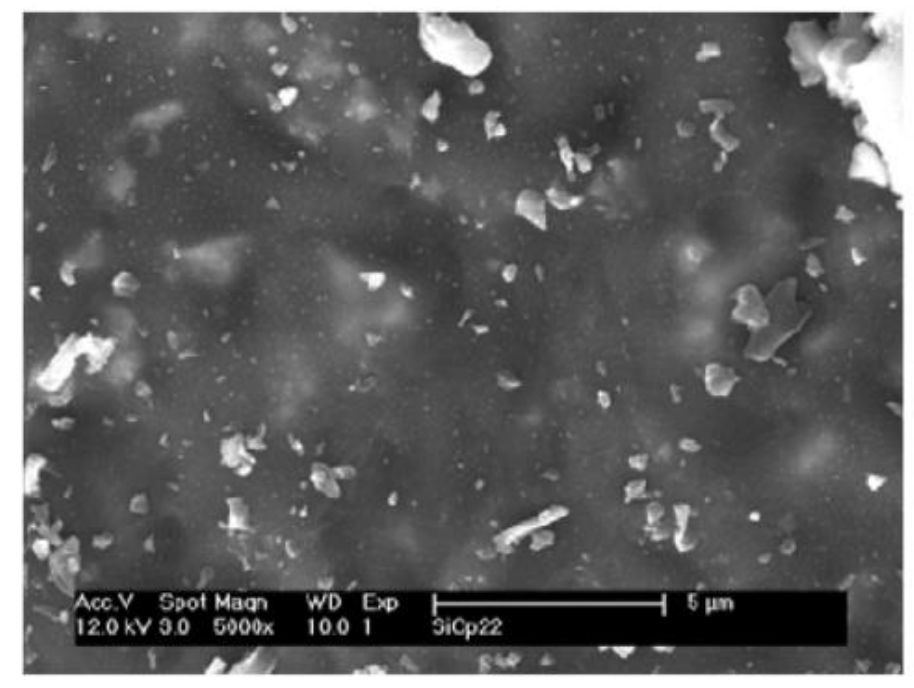

$5 \mu \mathrm{m}$

Figure 14: SEM image of a Si-C composite from PVC precursor (clear particles are silicon) ${ }^{83}$

Various precursors can be used. One important feature is the mass loss during thermal treatment. At $900{ }^{\circ} \mathrm{C}$, some precursors have very large mass losses (from more than $90 \%$ for cellulose and sucrose, down to $44 \%$ for some pitch) which makes them difficult to use due to the large gas treatment/energy recovery unit which has to be implemented:

Among other criteria, the aromatic content of the pitch is interesting as it will favor crystalline carbon. Oxygen content is important as high content will favor the reticulation and the formation of hard carbons. Silicon in carbon matrix is well documented. Erreur! signet non défini.84,19,65,85,86,87 Carbon matrix enable ionic and electric conductivities and helps to form a more stable SEI. ${ }^{19,65}$ 
Initial coulombic efficiencies (ICE) of Si/C composites are very variable. PVC and pitches as precursors coupled with nano-silicon have the highest values $(78-80 \%)^{59,88,85}$ Lignin yield to lower coulombic efficiency due to its higher oxygen content $\left(71.6 \%\right.$ ICE) ${ }^{83}$.

A good summary of all those approaches have been made by combining several of them. Hu et al. have mixed nano-silicon particles with micrometric graphite and CMC as binder. The blend is then dried and pyrolyzed at $900^{\circ} \mathrm{C}$ : silicon nanoparticles cover the graphite surface. ${ }^{89}$ Then, pitch dissolved in THF is added and pyrolyzed at $900^{\circ} \mathrm{C}$ : a pitch-based carbon layer is formed around the silicon on graphite particles. Then, the particles are placed in a CVD equipment and a carbon layer coming from acetylene decomposition at $700^{\circ} \mathrm{C}$ is deposited on the particles to form graphite@Si-Cex-cmc@ $\mathrm{C}_{\text {ex-pitch }} @ \mathrm{C}_{\text {ex-CVD. }}$. Those complex particles have carbon coming from 4 different sources and forming four successively layers, one of them containing also silicon. Liquid and gaseous processes are used (we can note that the first Si-graphite mixing could have been done by powder mixing). This material has a first discharge capacity of $762 \mathrm{mAh} / \mathrm{g}$ and then the capacity stabilized around $600 \mathrm{mAh} / \mathrm{g}$ from cycle 80 to 140 . This demonstrates that very good electrochemical performances can be obtained with silicon and complex carbon structure/texture. The challenge now is to obtain very good electrochemical performances with more simple structure and this implies a good knowledge of carbon and silicon chemistries.

\section{Conclusion}

Silicon has a very high specific capacity for Li-ion batteries anodes ( $3579 \mathrm{~mA} \mathrm{~h} \mathrm{~g}{ }^{-1}$ based on the $\mathrm{Li}_{15} \mathrm{Si}_{4}$ formation) and do not form dendrites, which is a strong advantage over lithium, the other potential high capacity anode material. Silicon has two disadvantages: cracking during electrochemical cycling, which can be solved by using particles smaller than $150 \mathrm{~nm}$; and limited cycling stability due to the continuous formation of SEI (solid electrolyte Interphase). SEI is due to silicon surfaces reaction with electrolyte. Those reactions are limited with carbon, especially graphite, but carbon-based material have capacities limited to $372 \mathrm{~mA} \mathrm{~h} \mathrm{~g}^{-1}$. Silicon nanoparticles hybridization with carbon can benefit from both interests: high silicon capacity and high carbon stability. This can be made possible by making a carbon shell around the silicon. Formation of silicon carbide should be avoided and, therefore, limits the type of carbon to "cokes" that can be obtained below $1000{ }^{\circ} \mathrm{C}$. Various ways have been tested: solid, liquid and gaseous carbon precursors, usually followed by a thermal treatment to increase carbon crystallinity. Simple coating and complex structure (carbon hollow structure around $\mathrm{Si}$, pomegranate) have been demonstrated at laboratory scales. Very good performances can be obtained with silicon and complex structure. It validates some principles to improve silicon stability: use Si particles with diameter below $150 \mathrm{~nm}$, protect the silicon surface with a carbon coating and enabling swelling without electrode cracking. One challenge for academic studies is to increase the overall active material stability. For larger use, the challenge now is to obtain very good performances with simple and cheap structure and this implies a good knowledge of both carbon and silicon chemistries.

Direct carbon coating techniques in line with silicon particles synthesis seems to be the most efficient way, among them laser pyrolysis has demonstrated large scale capacities. Integration of nano-silicon in carbon matrix is also simple and exhibit good results, especially when using pitch as carbon precursors. 
${ }^{1}$ Whittingham, M. S. Electrical Energy Storage and Intercalation Chemistry. Science, 192 (4244), 1126 6, 1976

${ }^{2}$ C.Fang, X. Wang, Y.S. Meng, Key issues hindering a practical lithium metal anode, trends in chemistry, vol1, 2, 152-158, 2019

${ }^{3}$ Okamoto, H. Lithium-Silicon. Section III: Supplemental Literature Review. J. Phase Equilibria, 19 (5), 486-486, 1998.

${ }^{4}$ C.J. Wen, R.A. Huggins, Chemical diffusion in intermediate phases in the lithium-silicon system, J. Sol.Stat.Chem., 37; 3; Pages 271-278, 1981

${ }^{5} \mathrm{Li}, \mathrm{H}$. The Crystal Structural Evolution of Nano-Si Anode Caused by Lithium Insertion and Extraction at Room Temperature. Solid State Ion., 135 (1-4), 181-191, 2000

${ }^{6}$ Schott, T.; Robert, R.; Pacheco Benito, S.; Ulmann, P. A.; Lanz, P.; Zürcher, S.; Spahr, M. E.; Novák, P.; Trabesinger, S. Cycling Behavior of Silicon-Containing Graphite Electrodes, Part B: Effect of the Silicon Source. J. Phys. Chem. C 2017, 121 (46), 25718-25728, 2017

${ }^{7}$ Chon, M. J.; Sethuraman, V. A.; McCormick, A.; Srinivasan, V.; Guduru, P. R. Real-Time Measurement of Stress and Damage Evolution During Initial Lithiation of Crystalline Silicon. Phys. Rev. Lett., 12, 2011

${ }^{8}$ B. Key, R. Bhattacharyya, M. Morcrette, V. Seznec, J. M. Tarascon and C. P. Grey, Real-Time NMR Investigations of Structural Changes in Silicon Electrodes for Lithium-Ion Batteries, J. Am. Chem. Soc., 131, 9239-9249, 2009

${ }^{9}$ A. J. Morris, R. J. Needs, E. Salager, C. P. Grey and C. J. Pickard, Lithiation of Silicon via Lithium ZintlDefectComplexes from First Principles, Phys. Rev. B: Condens. Matter Mater. Phys., 87(17), 6-9, 2013

${ }^{10}$ Ogata K, Salager E, Kerr CJ, Fraser AE, Ducati C, Morris AJ, Hofmann S, Grey CP. Revealing lithium-silicide phase transformations in nano-structured silicon-based lithium ion batteries via in situ NMR spectroscopy. Nat Commun. 5:3217, 2014

${ }^{11}$ Okamoto, H. Lithium-Silicon. Section III: Supplemental Literature Review. J. Phase Equilibria, 19 (5), 486-486, 1998

12 Hatchard, T. D.; Dahn, J. R. In Situ XRD and Electrochemical Study of the Reaction of Lithium with Amorphous Silicon. J. Electrochem. Soc., 151 (6), A838, 2004

${ }^{13}$ Obrovac, M. N.; Christensen, L. Structural Changes in Silicon Anodes during Lithium Insertion/Extraction. Electrochem. Solid-State Lett., 7 (5), A93, 2004

${ }^{14}$ Touidjine, A. PhD thesis, Optimisation de l'électrode négative à base de silicium pour les batteries lithiumion, Université de Picardie Jules Vernes, 2016.

15 Okamoto, H. The Li-Si (Lithium-Silicon) System., 11 (3), 7, 1990

${ }^{16}$ Schott, T.; Robert, R.; Pacheco Benito, S.; Ulmann, P. A.; Lanz, P.; Zürcher, S.; Spahr, M. E.; Novák, P.; Trabesinger, S. Cycling Behavior of Silicon-Containing Graphite Electrodes, Part B: Effect of the Silicon Source. J. Phys. Chem. C 2017, 121 (46), 25718-25728, 2017

${ }^{17}$ Chon, M. J.; Sethuraman, V. A.; McCormick, A.; Srinivasan, V.; Guduru, P. R. Real-Time Measurement of Stress and Damage Evolution During Initial Lithiation of Crystalline Silicon. Phys. Rev. Lett., 12, 2011

${ }^{18}$ McDowell, M. T.; Lee, S. W.; Nix, W. D.; Cui, Y. 25th Anniversary Article: Understanding the Lithiation of Silicon and Other Alloying Anodes for Lithium-Ion Batteries. Adv. Mater., 25 (36), 4966-4985, 2013

${ }^{19}$ Obrovac, M. N.; Chevrier, V. L. Alloy Negative Electrodes for Li-Ion Batteries. Chem. Rev., 114 (23), 1144411502, 2014

${ }^{20}$ Chen, H.; He, S.; Hou, X.; Wang, S.; Chen, F.; Qin, H.; Xia, Y.; Zhou, G. Nano-Si/C Microsphere with Hollow Double Spherical Interlayer and Submicron Porous Structure to Enhance Performance for Lithium-Ion Battery Anode. Electrochimica Acta 2019, 312, 242-250, 2019.

${ }^{21}$ Kasavajjula, U.; Wang, C.; Appleby, A. J. Nano- and Bulk-Silicon-Based Insertion Anodes for Lithium-Ion Secondary Cells. J. Power Sources, 163 (2), 1003-1039, 2007

${ }^{22}$ McDowell, M. T.; Lee, S. W.; Nix, W. D.; Cui, Y. 25th Anniversary Article: Understanding the Lithiation of Silicon and Other Alloying Anodes for Lithium-Ion Batteries. Adv. Mater., 25 (36), 4966-4985, 2013

${ }^{23}$ Hanne Flåten Andersen, Carl Erik Lie Foss, Jorunn Voje, Ragnar Tronstad, Tommy Mokkelbost, Per Erik Vullum, Asbjørn Ulvestad, Martin Kirkengen \& Jan Petter Mæhlen, Silicon-Carbon composite anodes from industrial battery grade silicon; Nature Scientific Reports, vol 9, n 14814; 2019

${ }^{24}$ Graetz, J.; Ahn, C. C.; Yazami, R.; Fultz, B. Highly Reversible Lithium Storage in Nanostructured Silicon. Electrochem. Solid-State Lett., 6 (9), A194, 2003

${ }^{25}$ Maranchi, J. P.; Hepp, A. F.; Kumta, P. N. High Capacity, Reversible Silicon Thin-Film Anodes for Lithium-lon Batteries. Electrochem. Solid-State Lett., 6 (9), A198. 2003

${ }^{26}$ Cui, L.-F.; yang, Y.; Hsu, C.-M.; Cui, Y. Carbon-Silicon Core-Shell Nanowires as High Capacity Electrode for Lithium Ion Batteries. Am. Chem. Soc., 9 (9), 3370-3374, 2009 
${ }^{27}$ Wu, H.; Chan, G.; Choi, J. W.; Ryu, I.; Yao, Y.; McDowell, M. T.; Lee, S. W.; Jackson, A.; Yang, Y.; Hu, L.; Cui, Y. Stable Cycling of Double-Walled Silicon Nanotube Battery Anodes through Solid-Electrolyte Interphase Control. Nat. Nanotechnol., 7 (5), 310-315, 2012

28 Obrovac, M. N.; Chevrier, V. L. Alloy Negative Electrodes for Li-Ion Batteries. Chem. Rev, 114 (23), 1144411502. 2014

${ }^{29}$ Sourice, J. PhD thesis, Synthèse de nanocomposites cœur-coquille silicium carbone par pyrolyse laser double étage : application à l'anode de batterie lithium-ion, Université Paris Sud, Paris XI, 2015

${ }^{30}$ Cannon, W. R.; Danforth, S. C.; Flint, J. H.; Haggerty, J. S.; Marra, R. A. Sinterable Ceramic Powders from Laser-Driven Reactions: I, Process Description and Modeling. J. Am. Ceram. Soc., 65 (7), 324-330, 1982

${ }^{31}$ N.Herlin-Boime, M. Mayne-L'Hermite, C. Reynaud, Synthesis of covalent Nanoparticules by $\mathrm{CO}_{2}$ laser, Encyclopedia of Nanoscience and Nanotechnology, 10, 1-26, 2004

32 Philippe, B.; Dedryvère, R.; Allouche, J.; Lindgren, F.; Gorgoi, M.; Rensmo, H.; Gonbeau, D.; Edström, K. Nanosilicon Electrodes for Lithium-Ion Batteries: Interfacial Mechanisms Studied by Hard and Soft X-Ray Photoelectron Spectroscopy. Chem. Mater., 24 (6), 1107-1115, 2012

${ }^{33}$ Verma, P.; Maire, P.; Novák, P. A Review of the Features and Analyses of the Solid Electrolyte Interphase in LiIon Batteries. Electrochimica Acta, 55 (22), 6332-6341, 2010

${ }^{34}$ Pereira-Nabais, C.; Światowska, J.; Chagnes, A.; Ozanam, F.; Gohier, A.; Tran-Van, P.; Cojocaru, C.-S.; Cassir, M.; Marcus, P. Interphase Chemistry of Si Electrodes Used as Anodes in Li-Ion Batteries. Appl. Surf. Sci., 266, 5-16, 2013

${ }^{35}$ Aurbach, D. A Comparative Study of Synthetic Graphite and Li Electrodes in Electrolyte Solutions Based on Ethylene Carbonate-Dimethyl Carbonate Mixtures. J. Electrochem. Soc., 143 (12), 3809, 1996

${ }^{36}$ Arreaga-Salas, D. E.; Sra, A. K.; Roodenko, K.; Chabal, Y. J.; Hinkle, C. L. Progression of Solid Electrolyte Interphase Formation on Hydrogenated Amorphous Silicon Anodes for Lithium-Ion Batteries. J. Phys. Chem. C, 116 (16), 9072-9077, 2012

${ }^{37} \mathrm{Xu}, \mathrm{K}$. Nonaqueous Liquid Electrolytes for Lithium-Based Rechargeable Batteries. Chem. Rev., 104 (10), $4303-$ 4418, 2004

${ }^{38}$ Peng Li, Guoqiang Zhao, Xiaobo Zheng, Xun Xu, Chenghao Yao, Wenping Sun, Shi Xue Dou, Recent progress on silicon-based anode materials for practical lithium-ion battery applications, Energy Storage Materials, Volume 15, Pages 422-446, 2018

39 Yoshino, A.; Nakajima,T; Patent JP9769585 SECONDARY BATTERY, 1985

${ }^{40}$ C. Pilot, Avicenne presentation, 7th March, Cleveland, Ohio, 2018,

${ }^{41}$ I.-S. Kim, G.E. Blomgren, P.N. Kumta, Tiltel XX, J. Power Sources 130; 275, 2004.

${ }^{42}$ Varadachari et al, Modelling simul mater sci eng, 17, 075006, 2009

${ }^{43}$ Coulon, M.; Reynvaan, C.; Maire, J. Le carbone en électrotechnique., 33, 1994

${ }^{44}$ Son, I., Hwan Park, J., Kwon, S. et al. Silicon carbide-free graphene growth on silicon for lithium-ion battery with high volumetric energy density. Nat Commun 6, 7393, 2015.

${ }^{45}$ Graczyk-Zajac, M.; Mera, G.; Kaspar, J.; Riedel, R. Electrochemical Studies of Carbon-Rich Polymer-Derived SiCN Ceramics as Anode Materials for Lithium-Ion Batteries. J. Eur. Ceram. Soc., 30 (15), 3235-3243, 2010

${ }^{46}$ P. M. Attia, Supratim Das, S. J. Harris, Martin Z. Bazant2,5 and William C. Chueh, Electrochemical Kinetics of SEI Growth on Carbon Black: Part I. Experiments, Journal of The Electrochemical Society, 166(4):E97-E106, 2019

${ }^{47}$ M.Gutierrez, unpublished result

${ }^{48}$ A. Concheso, R. Santamaria, R Menendez, J.M. Jimenez-Mateos, R. Alcantara, G.F. Ortiz,P. Lavela, J.L. Tirado, Effect of oxidation on the perfroamnces of low temperature petroleum cokes as anodes in lithium ion batteries, J.Appl Electrochem, 38; 899-906; 2009

${ }^{49}$ Marsh, H., A tribute to Philip L Walker. Carbon, 29(6): p. 703-704, 1991

${ }^{50}$ Yong, Y.; Fan, L.-Z. Silicon/Carbon Nanocomposites Used as Anode Materials for Lithium-Ion Batteries. Ionics, 19 (11), 1545-1549, 2013

${ }^{51}$ Buiel, E.; Dahn, J. R. Li-Insertion in Hard Carbon Anode Materials for Li-Ion Batteries. Electrochimica Acta, 45 (1-2), 121-130, 1999

52 Müller, D. R. Artificial Graphite for Lithium Ion Batteries. P35, London presentation 2011

53 J. Sourice, A Quinsac, Y. Leconte, O. Sublemontier, W. Porcher, C.Haon, A. Bordes, E. De Vito, A. Boulineau, S. Jouanneau Si Larbi, N. Herlin-Boime, C. Reynaud, One-Step Synthesis of Si@C Nanoparticles by Laser Pyrolysis: High-Capacity Anode Material for Lithium-Ion Batteries, ACS Appl. Mater. Interfaces, 7, 12, 66376644, 2015

${ }^{54}$ Xiaohan Wan, PhD thesis, University $f$ New south wales, 2019 
${ }^{55}$ Graczyk-Zajac, M.; Mera, G.; Kaspar, J.; Riedel, R. Electrochemical Studies of Carbon-Rich Polymer-Derived SiCN Ceramics as Anode Materials for Lithium-Ion Batteries. J. Eur. Ceram. Soc., 30 (15), 3235-3243, 2010

${ }^{56}$ Datta, M. K.; Kumta, P. N. Silicon, Graphite and Resin Based Hard Carbon Nanocomposite Anodes for Lithium Ion Batteries. J. Power Sources, 165 (1), 368-378, 2007

${ }^{57}$ Li, P.; Zhao, G.; Zheng, X.; Xu, X.; Yao, C.; Sun, W.; Dou, S. X. Recent Progress on Silicon-Based Anode Materials for Practical Lithium-Ion Battery Applications. Energy Storage Mater., 15, 422-446, 2018

${ }^{58}$ Du, L.; Wu, W.; Luo, C.; Zhao, H.; Xu, D.; Wang, R.; Deng, Y. Lignin Derived Si@C Composite as a HighPerformance Anode Material for Lithium Ion Batteries. Solid State Ion., 319, 77-82, 2018

${ }^{59}$ Saint, J.; Morcrette, M.; Larcher, D.; Laffont, L.; Beattie, S.; Pérès, J.-P.; Talaga, D.; Couzi, M.; Tarascon, J.-M. Towards a Fundamental Understanding of the Improved Electrochemical Performance of Silicon-Carbon Composites. Adv. Funct. Mater. 17 (11), 1765-1774, 2007

${ }^{60}$ Dang, A.; Li, H.; Li, T.; Zhao, T.; Xiong, C.; Zhuang, Q.; Shang, Y.; Chen, X.; Ji, X. Preparation and Pyrolysis Behavior of Modified Coal Tar Pitch as C/C Composites Matrix Precursor. J. Anal. Appl. Pyrolysis, 119, 18-23, 2016

${ }^{61}$ Dupupet, G. Fibres de carbone., 22, 2008

${ }^{62}$ European Carbon and Graphite association. Status of Coal Tar Pictch, High Temperature (CTPht) as an Intermediate in the Manufacture of Carbon and Graphite Products. 9; 2016.

${ }^{63}$ Savage, G. Carbon-Carbon Composites; 2012.

${ }^{64}$ Tarascon, J.-M.; Morcrette, M.; Saint, J.; Aymard, L.; Janot, R. On the Benefits of Ball Milling within the Field of Rechargeable Li-Based Batteries. Comptes Rendus Chim., 8 (1), 17-26, 2005

${ }^{65}$ Bridel, J.-S. PhD thesis, Optimisation de composites silicium-polymère-carbone pour électrodes négatives d'accumulateurs lithium-ion, Université de Picardie Jules Vernes, 2010

${ }^{66}$ Costa, P. Nanomatériaux - Structure et Élaboration. Tech. Ing. 2001

${ }^{67}$ Kasavajjula, U.; Wang, C.; Appleby, A. J. Nano- and Bulk-Silicon-Based Insertion Anodes for Lithium-lon Secondary Cells. J. Power Sources, 163 (2), 1003-1039, 2007

${ }^{68}$ Li, P.; Zhao, G.; Zheng, X.; Xu, X.; Yao, C.; Sun, W.; Dou, S. X. Recent Progress on Silicon-Based Anode Materials for Practical Lithium-Ion Battery Applications. Energy Storage Mater., 15, 422-446, 2018

${ }^{69} \mathrm{Nist}$ data base https://webbook.nist.gov/cgi/cbook.cgi?ID=C74862\&Mask=1\#Thermo-Gas, consulted on 06/11/2020

${ }^{70}$ Chaukulkar RP, de Peuter K, Stradins P, Pylypenko S, Bell JP, Yang Y, Agarwal S. Single-step plasma synthesis of carbon-coated silicon nanoparticles. ACS Appl Mater Interfaces.;6(21):19026-34, 2014

${ }^{71}$ R.P. Chaukulkar, K.D. Peuter, P. Stradin, S. Pylypenko, J.P. Bell, Y.Yang, S. Agarwal, single step plamsa synthesis of carbon coated silicon nanoparticles, ACS applids materials\& interfaces, 6, 21, 19026-19034, 2014

72 Hurd, C. D. Pyrolysis of unsaturated hydrocarbons. Ind. Eng. Chem.,26, 50-55, 1934

73 P.L. Silvestrelli, F. Toigo, F. Ancilotto, Acetylene on Si(100) from first principles: adsorption geometries, equilibrium coverages and thermal decomposition, J.Chem.Phys.,114, 19, 2001.

${ }^{74} \mathrm{~F}$. Tenegal, METHOD FOR PRODUCING MULTILAYER SUBMICRON PARTICLES BY LASER PYROLYSIS patent EP2872444 (B1), 2012

${ }^{75}$ A. Alavarez Barragan, G. Nava, N.J. Wagner, L. Mangolini, Silicon-carbon composites for lithium-ion batteries: A comparative study of different carbon deposition approaches, Journal of Vacuum Science \& Technology B 36, 011402, 2018

${ }^{76}$ J.Yang, Y.X. Wang, S.L. Chou, R. Zhang, Y. Xu, J.Fan, W. Shang, H.K. Liu, D. Zhao, S.X. Dou, Yolk-shell silicon mesoporous carbon anode with compact solid electrolute interphase film for superior lithium-ion batteries, Nano Energy, 18, 133-142,2015

${ }^{77}$ Peng Guan, J.Li, T. Lu, T. Guan, Z. Ma, Z. Peng, X. Zhu, L. Zhang, Facile and Scalable Approach To Fabricate Granadilla-like Porous-Structured Silicon-Based Anode for Lithium Ion Batteries, ACS Appl. Mater. Interfaces, 10, 40, 34283-34290, 2018

78 Mochida, I.; Zeng, S.-M.; Korai, Y.; Hino, T.; Toshima, H. The Introduction of a Skin-Core Structure in Mesophase Pitch Fibers through a Successive Stabilization by Oxidation and Solvent Extraction. Carbon, 29 (1), 23-29, 1991

${ }^{79}$ Kim, S. Y.; Lee, J.; Kim, B.-H.; Kim, Y.-J.; Yang, K. S.; Park, M.-S. Facile Synthesis of Carbon-Coated Silicon/Graphite Spherical Composites for High-Performance Lithium-Ion Batteries. ACS Appl. Mater. Interfaces, 8 (19), 12109-12117, 2016

${ }^{80}$ Paireau, C.; Jouanneau, S.; Ammar, M.-R.; Simon, P.; Béguin, F.; Raymundo-Piñero, E. Si/C Composites Prepared by Spray Drying from Cross-Linked Polyvinyl Alcohol as Li-lon Batteries Anodes. Electrochimica Acta, 174, 361-368, 2015 
${ }^{81}$ Li, Y.; Liu, W.; Long, Z.; Xu, P.; Sun, Y.; Zhang, X.; Ma, S.; Jiang, N. Si@C Microsphere Composite with Multiple Buffer Structures for High-Performance Lithium-Ion Battery Anodes. Chem. - Eur. J., 24 (49), 12912-12919 2018

${ }^{82}$ Shen, T.; Xia, X.; Xie, D.; Yao, Z.; Zhong, Y.; Zhan, J.; Wang, D.; Wu, J.; Wang, X.; Tu, J. Encapsulating Silicon Nanoparticles into Mesoporous Carbon Forming Pomegranate-Structured Microspheres as a HighPerformance Anode for Lithium Ion Batteries. J. Mater. Chem. A, 5 (22), 11197-11203, 2017

${ }^{83}$ Saint, J., PhD thesis, Matériaux d'électrode négative pour accumulateurs à ions lithium : Etude des systèmes binaires Li-Ga et Li-B et des composites silicium-carbone, Université de Picardie Jules Vernes, 2005.

${ }^{84}$ Desrues, A. PhD thesis, Matériaux Composites Si@C Nanostructurés Pour Anodes de Batterie Li-lon à Haute Densité d'énergie. Relations Entre Structure/Morphologie et Mécanismes de Dégradation, Université Paris Sud, 2019

${ }^{85}$ Escamilla-Pérez, A.; Roland, A.; Giraud, S.; Guiraud, C.; Virieux, H.; Demoulin, K.; Oudart, Y.; Louvain, N.; Monconduit, L. Pitch-Based Carbon/Nano-Silicon Composite, an Efficient Anode for Li-lon Batteries. RSC Adv., 9 (19), 10546-10553, 2019

${ }^{86}$ Yong, Y.; Fan, L.-Z. Silicon/Carbon Nanocomposites Used as Anode Materials for Lithium-Ion Batteries. Ionics, 19 (11), 1545-1549, 2013

${ }^{87}$ Xing, W. Pyrolysed Pitch-Polysilane Blends for Use as Anode Materials in Lithium Ion Batteries. Solid State Ion., 93 (3-4), 239-244, 1997

${ }^{88}$ Liu, Y.; Matsumura, T.; Imanishi, N.; Hirano, A.; Ichikawa, T.; Takeda, Y. Preparation and Characterization of Si/C Composite Coated with Polyaniline as Novel Anodes for Li-Ion Batteries. Electrochem. Solid-State Lett., $8(11)$, A599, 2005

${ }^{89} \mathrm{Hu}, \mathrm{X} .$, Huang, S., Hou, X. et al. A Double Core-shell Structure Silicon Carbon Composite Anode Material for a Lithium Ion Battery. Silicon 10, 1443-1450, 2018 